\title{
Health-Related Quality of Life in Patients with Chronic Myeloid Leukemia Treated with First- Versus Second-Generation Tyrosine Kinase Inhibitors
}

\author{
Adi Shacham Abulafia 1,2,*, Sivan Shemesh ${ }^{2}$, Lena Rosenmann 1, Tamar Berger 1,2, Avi Leader 1,2, \\ Giora Sharf ${ }^{3}$, Pia Raanani ${ }^{1,2}$ and Uri Rozovski ${ }^{1,2}$ \\ 1 Institute of Hematology, Davidoff Cancer Center, Beilinson Hospital, Rabin Medical Center, \\ Petah-Tikva 49100, Israel; lenaro1@clalit.org.il (L.R.); tamaritayberger@gmail.com (T.B.); \\ avileader@yahoo.com (A.L.); praanani@012.net.il (P.R.); uriro1@clalit.org.il (U.R.) \\ 2 Sackler School of Medicine, Tel Aviv University, Tel Aviv 6997801, Israel; shesivan1@gmail.com \\ 3 Israeli CML Patients Organization, 5 Ehud Manor st., Netanya 4265952, Israel; giora1@inter.net.il \\ * Correspondence: shacham.adi@gmail.com; Tel.: +972-(0)543040797
}

Received: 28 September 2020; Accepted: 21 October 2020; Published: 25 October 2020

\begin{abstract}
The life expectancy of patients with chronic myeloid leukemia (CML) approaches that of the age-matched population and quality of life (QOL) issues are becoming increasingly important. To describe patients' characteristics and assess QOL, we delivered a 30-item core questionnaire, a 24-item CML-specific questionnaire, both from the European Organization for Research and Treatment of Cancer (EORTC), and additional health-related items to 350 patients. Among 193 patients who completed the questionnaires, 139 received either imatinib $(n=70,33 \%)$, dasatinib $(n=45,23 \%)$ or nilotinib $(n=24,12 \%)$. Patients' median age was 58 (range: 23 to 89$)$ years and $86(63 \%)$ were males. Stratifying patients by treatment, we recognized two distinct populations. In comparison to patients on dasatinib and nilotinib, patients on imatinib were two decades older, had a longer duration of disease and current treatment, experienced fewer limitations on daily activities $(p=0.02)$, less fatigue $(p=0.001)$, lower degree of impaired body image $(p=0.022)$ and less painful episodes $(p=0.014)$. Similarly, they had better emotional functioning, were less worried, stressed, depressed or nervous $(p=0.01)$ and were more satisfied with their treatment $(p=0.018)$. Not only does age associate with current treatments, but it also predicts how patients perceive QOL. Young patients express impaired QOL compared with elderly patients.
\end{abstract}

Keywords: quality of life; chronic myeloid leukemia; tyrosine kinase inhibitors; patient-reported outcome

\section{Introduction}

In 2001, imatinib was approved for the treatment of patients with chronic myeloid leukemia (CML) [1]. Since then, several generations of newer, more potent tyrosine kinase inhibitors (TKIs) entered the market. As of 2020, five drugs have been approved in the US and Europe for CML. Yet, the EUTOS registry data indicate that three drugs are most commonly used. Patients in chronic-phase CML typically receive lifelong treatment with either imatinib, dasatinib or nilotinib [2]. Treatment with any of these drugs is associated with high survival expectancy. Nonetheless, they come with a price of adverse effects, where some are common to all TKIs and some are drug-specific.

The choice of TKI is tailored based on drug availability, patients and disease characteristics and whether treatment discontinuation is considered a goal [3]. Since, nowadays, the life expectancy of patients with CML approaches that of the general age-matched population [4,5], quality of life (QOL) issues are becoming increasingly important. QOL studies typically focused on tolerability which is 
only one aspect of life quality $[3,6,7]$ and only limited data are available on the QOL of patients that are treated with these drugs outside clinical trials.

In an era of patient-centered medicine, patients-oriented research that brings out patients' perspectives provides an additional layer of valuable knowledge. Using patients reported outcomes (PROs) unravels patients' preferences and may ultimately leads to improved patient-physician communication, improved adherence to treatment and improved overall QOL.

In this study, we use PRO measures (PROMs) to assess the QOL and symptom burden in 139 patients with CML, treated with one of the three most commonly used TKIs-imatinib, dasatinib and nilotinib—outside clinical trials.

\section{Material and Methods}

This nationwide study was a joint initiative of the Israeli CML patients' organization and the Institute of Hematology at the Rabin Medical Center, Israel. The study was approved by our local institutional review board (0034-19-RMC). The study included any adult patient ( $\geq 18$ years old) with a diagnosis of CML who received at least one TKI for at least 3 months and agreed to complete self-reported questionnaires. We approached patients either by e-mails that were sent to members of the CML patients' organization or by their treating physician while waiting for their appointment, if treated in our hospital. Patients who agreed to participate completed a survey booklet or a computerized version of it. The booklet was written in Hebrew and included the following questionnaires: a 30-item core questionnaire (QLQ-C30), and a 24-item CML-specific (QLQ-CML24) questionnaire, both provided by the European Organization for Research and Treatment of Cancer (EORTC). Additional questions included demographics and clinical data, and items involving anxiety, sexual and work function, family planning and adherence to treatment. A complete version of the protocol was added to the Supplementary data 1 .

The QLQ-30 consists of (i) 5 functioning scales: physical, role, emotional, cognitive and social, (ii) 3 symptoms' scales: fatigue, nausea/vomiting and pain, (iii) 6 single-item scales: dyspnea, insomnia, appetite loss, constipation, diarrhea and financial impact and (iv) the global health status quality of life scale [8]. The Hebrew version of this questionnaire was approved by the EORTC, and was already used in previous studies (https://www.eortc.org/). The alpha Cronbach test for internal consistency of the QLQ-30 subscales ranged between 0.69 and 0.92 .

The QLQ-CML24 consists of impact on daily life, symptom burden, impact on worry/mood, body image problems, satisfaction with care and information and satisfaction with social life. The items were scaled and scored according to the EORTC recommendations [9]. To validate the Hebrew version, we used the backward-forward translation strategy as previously described [10,11]. Briefly, 2 independent translators fluent in English and Hebrew translated the English version and the Hebrew version was re-translated to English. This process continued until the final version was approved by the EORTC committee. The alpha Cronbach test for internal consistency of the QLQ-CML24 subscales ranged between 0.75 and 0.91 .

All scales and single-item measures were standardized and the score ranges from 0 to 100 . A high score for functional and QOL items/scales represents better function and QOL. A high score in symptoms items represents worse symptomatology.

We used the Mann-Whitney test to compare medians and $\chi 2$ to compare categorical variables.

\section{Results}

\subsection{Patients' Characteristics}

Overall, 193 patients completed the questionnaires, the median age was 58 years (range: 23 to 89 ) and of those, 102 patients (53\%) were males. Time from diagnosis ranged between less than a year to 46 years (median: 7 years). In this report, we included 139 patients $(72 \%)$ who received either imatinib $(n=70,33 \%)$, dastainib $(n=45,23 \%)$ or nilotinib $(n=24,12 \%)$ and did not include the few patients 
who received bosutinib $(n=8,4 \%)$ or ponatinib $(n=2,1 \%)$, patients who discontinued treatment ( $n=22,11 \%)$ or patients with missing data regarding the TKI they received $(n=22,11 \%)$.

Stratifying patients by treatment, we recognized two distinct populations with unique demographics and clinical characteristics: patients on imatinib and those on second-generation TKIs (dasatinib or nilotinib). Patients on imatinib were on average two decades older (Table 1), had longer duration of disease and longer exposure to current drug (Table 2) in comparison to patients on dasatinib and nilotinib.

Table 1. Demographic characteristics of study population.

\begin{tabular}{|c|c|c|c|c|c|}
\hline Characteristics & $\begin{array}{c}\text { Imatinib } \\
n=70\end{array}$ & $\begin{array}{c}\text { Dasatinib } \\
\quad n=45\end{array}$ & $\begin{array}{c}\text { Nilotinib } \\
n=24\end{array}$ & $\begin{array}{c}\text { Total } \\
n=139\end{array}$ & $p$ Value \\
\hline Age, years, median (range) & 67 (32 to 89$)$ & 47 (23 to 78$)$ & $50(26$ to 85$)$ & $58(23$ to 89$)$ & $<0.0001$ \\
\hline \multicolumn{6}{|l|}{ Gender $n(\%) *$} \\
\hline male & $43(62)$ & $28(64)$ & $15(63)$ & $86(63)$ & \multirow{2}{*}{0.99} \\
\hline female & $26(38)$ & $16(36)$ & $9(37)$ & $51(37)$ & \\
\hline \multicolumn{6}{|l|}{ Family status * } \\
\hline singles, $n(\%)$ & $3(5)$ & $13(30)$ & $4(17)$ & $20(15)$ & \multirow{2}{*}{0.001} \\
\hline married, $n(\%)$ & $62(95)$ & $30(70)$ & $20(83)$ & $112(85)$ & \\
\hline number of children, median (range) & $3(0$ to 15$)$ & $2(0$ to 10$)$ & $2(0$ to 6$)$ & $3(0$ to 15$)$ & 0.06 \\
\hline \multicolumn{6}{|l|}{ Education level, $n(\%) *$} \\
\hline elementary & $4(6)$ & $3(7)$ & $3(12)$ & $10(7)$ & \multirow{3}{*}{0.6} \\
\hline high school & $24(36)$ & $19(42)$ & $6(25)$ & $49(36)$ & \\
\hline high education & $39(58)$ & $23(51)$ & $15(63)$ & $77(57)$ & \\
\hline \multicolumn{6}{|l|}{ Level of religiosity, $n(\%) *$} \\
\hline secular & $40(62)$ & $30(68)$ & $13(57)$ & $83(63)$ & \multirow{4}{*}{0.93} \\
\hline traditional & $14(22)$ & $7(16)$ & $16(26)$ & $27(21)$ & \\
\hline religious & $10(15)$ & $6(14)$ & $4(17)$ & $20(15)$ & \\
\hline ultra-orthodox & $1(1)$ & $1(2)$ & 0 & $2(1)$ & \\
\hline
\end{tabular}

Table 2. Disease characteristics of study population.

\begin{tabular}{|c|c|c|c|c|c|}
\hline Characteristics & $\begin{array}{l}\text { Imatinib } \\
n=70\end{array}$ & $\begin{array}{l}\text { Dasatinib } \\
n=45\end{array}$ & $\begin{array}{l}\text { Nilotinib } \\
n=24\end{array}$ & $\begin{array}{c}\text { Total } \\
n=139\end{array}$ & $p$ Value \\
\hline Duration of disease, months, median (range) & 10 (1 to 46$)$ & $4(<1$ to 15$)$ & $5(1$ to 14$)$ & $7(<1$ to 46$)$ & $<0.0001$ \\
\hline \multicolumn{6}{|l|}{ Previous TKIs, $n(\%)$} \\
\hline 0 & $41(59)$ & $23(51)$ & $8(33)$ & $72(52)$ & \multirow{3}{*}{0.3} \\
\hline 1 & $25(36)$ & $18(40)$ & $13(54)$ & $56(40)$ & \\
\hline$>2$ & $4(5)$ & $4(9)$ & $3(12)$ & $11(8)$ & \\
\hline $\begin{array}{l}\text { Duration of treatment with current TKI, } \\
\text { months, median (range) }\end{array}$ & $8(<1$ to 18$)$ & $2(<1$ to 11$)$ & $4(<1$ to 11$)$ & $4.3(<1$ to 18$)$ & $<0.0001$ \\
\hline
\end{tabular}

TKIs, Tyrosine Kinase Inhibitors.

\subsection{Symptom Burden-EORTC (The QLQ-30 and the QLQ-CML24)}

The EORTC questionnaires included 34 items related to symptoms that were experienced by patients within the last week. These items were grouped into 13 symptom scales. Overall, the symptomatic profile was more severe in patients who received second-generation TKIs. This trend was more pronounced in patients on nilotinib and was independently shown in both the cancer-specific 
EORTC QLQ-30 and in the CML-specific CML-24 (Figure 1). For example, in the EORTC QLQ-30 questionnaire, compared with patients on either dasatinib or nilotinib, patients on imatinib experienced lesser limitations on daily activities ( 38 and 47 vs. 25 , respectively, $p=0.02$ ), less fatigue ( 53 and 57 vs. 37 , respectively, $p=0.001$ ) and a lower degree of impaired body image (38 and 46 vs. 26, respectively, $p=0.022$ ). Similarly, in the QLQ-CML24 questionnaire, patients on imatinib reported less painful episodes compared with patients on nilotinib (28 vs. $47 . p=0.014$ ). Furthermore, the overall symptom burden was higher with nilotinib (41) compared with either dasatinib (27, $p=0.005)$ or imatinib $(30, p=0.018)$.

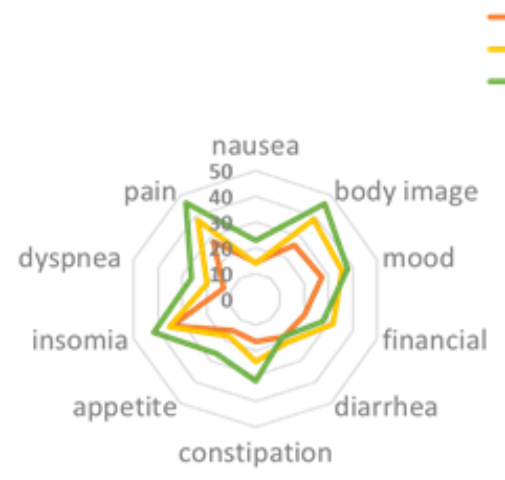

a

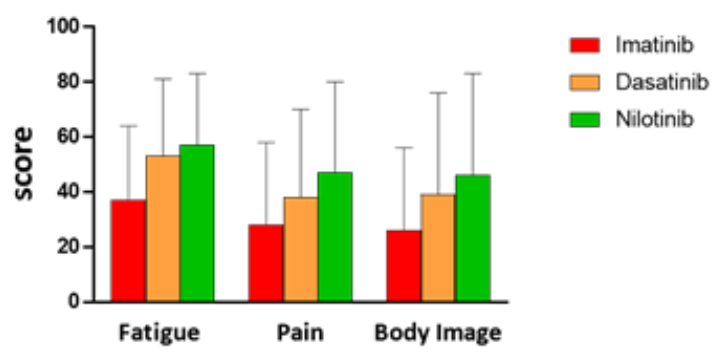

b

Figure 1. Symptom Burden on imatinib vs. dasatinib and nilotinib. Symptom burden according to EORTC QLQ-C30 and EORTC QLQ-CML24 in patients on imatinib, dasatinib or nilotinib. (a) A polar plot summarizes scores of 10 symptom-related items/scales. Higher scores represent worse symptomatology. As shown, patients on imatinib are represented in the inner circle, indicating less symptoms. (b) A bar graph showing that patients on imatinib report less fatigue and pain and a better body image. European Organization for Research and Treatment of Cancer Quality of Life Core Questioner 30 (EORTC QLQ-C30); European Organization for Research and Treatment of Cancer Quality of Life Questioner of Chronic myeloid Leukemia 24 (EORTC QLQ-CML24).

\subsection{Functional Status-EORTC (The QLQ-30 and the QLQ-CML24)}

Additionally, the EORTC questionnaires include 18 items that are grouped into eight scales. These scales are aimed to estimate patients' functional status. Compared with nilotinib, patients on imatinib had better emotional functioning and were less worried, stressed, depressed or nervous. The mean score of global emotional functioning was 77 for imatinib (standard deviation (S.D.) 24) and only 61 (S.D. 31) for nilotinib ( $p=0.009$ ) (Figure 2). Likewise, patients on imatinib were also more satisfied from the knowledge and treatment they received from their caregivers; the mean score on this scale was 41 (S.D. 37) for imatinib, 24 (S.D. 23) for dasatinib and only 19 (S.D. 26) for nilotinib ( $p=0.01$ ). 


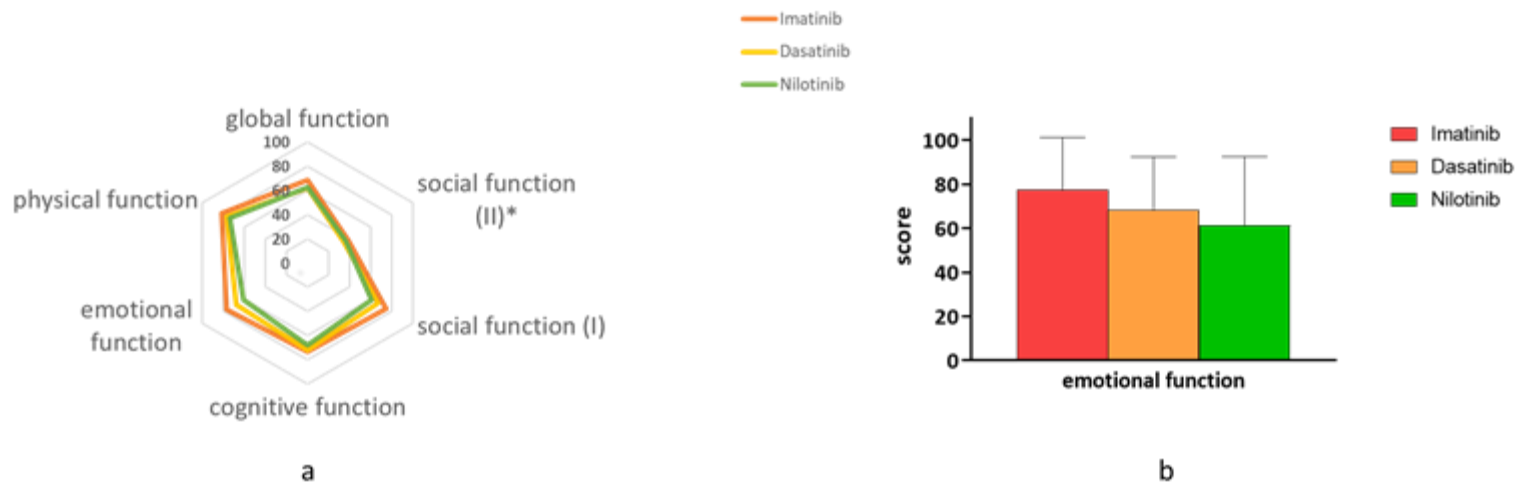

Figure 2. Functional Status on imatinib vs. dasatinib and nilotinib. Functional status according to QLQ30 and CML-24 in patients on imatinib, dasatinib or nilotinib. (a) A polar plot summarizes scores of 5 different aspects of function according to patient reports. Social function is represented in 2 scales (QLQ30 and CML-24). As shown, patients on imatinib are represented in the outer circle, indicating better function. (b) A bar graph showing that patients on imatinib report higher levels of emotional functioning. European Organization for Research and Treatment of Cancer Quality of Life Core Questioner 30 (EORTC QLQ-C30); European Organization for Research and Treatment of Cancer Quality of Life Questioner of Chronic myeloid Leukemia 24 (EORTC QLQ-CML24).

\subsection{Additional Health-Related (HR) Items}

In addition to the EORTC questionnaires, several items were added by us and are analyzed herein (Table 3).

Consistent with the results from the EORTC questionnaires, patients on imatinib reported better HR QOL during the last three months $(p=0.04)$ and more patients on imatinib reported that their overall QOL was not affected, or only mildly affected by the disease or treatment they received $(p=0.02)$.

Overall, as many as $44 \%(n=58)$ reported that their function at work was moderately or severely impaired and 35\% ( $n=38)$ reported that their function at home was impaired. Yet again, only 33\% $(n=22)$ of patients on imatinib reported significant work dysfunction compared with $56 \%(n=24)$ and $52 \%(n=12)$ of patients on dasatinib or nilotinib, respectively $(p=0.04)$ and likewise, only $24 \%(n=16)$ of patients on imatinib reported significant home dysfunction compared with $47 \%(n=21)$ and $46 \%$ $(n=11)$ of patients on dasatinib or nilotinib, respectively $(p=0.023)$. On the other hand, while $40 \%$ of patients $(\mathrm{N}=51)$ reported that their sexual function deteriorated during treatment, there were no differences across drugs.

In the questionnaire, we also included several items that might point to drug toxicity including breathing difficulties due to pleural effusion, hospitalization during the previous six months and referral to cardiovascular or pulmonary clinics. We did not find any difference across drugs in any of these questions, nor in the reported adherence rates. 
Table 3. Patients' reported outcomes—additional questions.

\begin{tabular}{|c|c|c|c|c|c|}
\hline Additional Questions & $\begin{array}{l}\text { Imatinib } \\
n=70\end{array}$ & $\begin{array}{c}\text { Dasatinib } \\
n=45\end{array}$ & $\begin{array}{l}\text { Nilotinib } \\
n=24\end{array}$ & $\begin{array}{c}\text { Total } \\
n=139\end{array}$ & $p$ Value \\
\hline $\begin{array}{l}\text { Grade your health condition during the last } 3 \\
\text { months *; mean (S.D.) }\end{array}$ & $5(1.2)$ & $4.5(1.3)$ & $4.5(1.5)$ & $4.8(1.3)$ & 0.04 \\
\hline \multicolumn{6}{|l|}{$\begin{array}{l}\text { Was your QOL during the last } 3 \text { months } \\
\text { affected by CML/treatment; } n(\%)\end{array}$} \\
\hline Yes & $26(41)$ & $26(61)$ & $17(71)$ & $69(53)$ & 0.02 \\
\hline No & $38(59)$ & $17(39)$ & $7(29)$ & $62(47)$ & \\
\hline \multicolumn{6}{|c|}{ Symptoms since the current drug started } \\
\hline \multicolumn{6}{|l|}{ Was your work function impaired?; $n(\%)$} \\
\hline Yes & $22(33)$ & $24(56)$ & $12(52)$ & $58(44)$ & 0.04 \\
\hline No & $45(67)$ & $19(44)$ & $11(48)$ & $75(56)$ & \\
\hline \multicolumn{6}{|l|}{ Was your home function impaired?; $n(\%)$} \\
\hline Yes & $16(24)$ & $21(47)$ & $11(46)$ & $48(35)$ & 0.023 \\
\hline No & $51(76)$ & $24(53)$ & $13(54)$ & $88(65)$ & \\
\hline \multicolumn{6}{|l|}{ Was your sexual function impaired?; $n(\%)$} \\
\hline Yes & $25(39)$ & $17(42)$ & $9(41)$ & $51(40)$ & 0.94 \\
\hline No & $39(61)$ & $23(58)$ & $13(59)$ & $75(60)$ & \\
\hline \multicolumn{6}{|l|}{$\begin{array}{c}\text { Were you followed at the } \\
\text { cardiology/vascular/pulmonology/neurology } \\
\text { clinic?; } n(\%)\end{array}$} \\
\hline Yes & $40(61)$ & $25(57)$ & $12(52)$ & $77(58)$ & 0.77 \\
\hline No & $26(39)$ & $19(43)$ & $11(48)$ & $56(42)$ & \\
\hline \multicolumn{6}{|l|}{$\begin{array}{l}\text { Did you have difficulties in breathing due to } \\
\text { fluids accumulation in your lungs?; } n(\%)\end{array}$} \\
\hline Yes & $8(13)$ & $9(21)$ & $4(18)$ & $21(16)$ & 0.5 \\
\hline No & $36(87)$ & $34(79)$ & $18(82)$ & $108(84)$ & \\
\hline \multicolumn{6}{|l|}{$\begin{array}{l}\text { Were you admitted to the hospital in the last } \\
\qquad 6 \text { months?; } n(\%)\end{array}$} \\
\hline Yes & $34(49)$ & $17(38)$ & $8(23)$ & $59(42)$ & 0.32 \\
\hline No & $36(51)$ & $28(62)$ & $16(67)$ & $80(58)$ & \\
\hline
\end{tabular}

${ }^{*}$ Health condition during the last month was graded between 0 and 6 (0-worst, 7-best). S.D., Standard Deviation; QOL, Quality of Life; CML, Chronic Myeloid Leukemia.

\section{Discussion}

In this "real-life" study, we used self-reported questionnaires to assess how patients perceive their QOL with imatinib, dasatinib and nilotinib, the three most common TKIs that are currently in use. Overall, we found that patients on imatinib expressed lower levels of distress and higher levels of satisfaction from the treatment that they received. Despite this, our study does not indicate that imatinib is a "better drug" or at least provides superior QOL.

Previous studies showed that age impacts health-related quality of life (HR QOL), but not necessarily in the expected direction. For example, in a pooled analysis of more than 6000 patients with cancer, social role and emotional functioning were better with increasing age [12]. Likewise, among 1420 women with breast cancer, HR QOL was better in older patients [13]. In line with these large-scale studies, in our study, patients on imatinib, who experienced improved HR QOL, were two decades older.

With a median age of 67 , most patients on imatinib are "baby boomers", born after World War II between 1946 and 1964. Compared with the "x generation" born between 1965 and 1976, boomers have a higher prevalence of "excellent" self-reported health [14]. Hence, differences between boomers, mostly on imatinib, and younger patients, mostly on second-generation TKIs, might reflect a sociological trend rather than "drug quality". Moreover, a recent study that also used the EORTC 
questionnaires found that dasatinib provided a superior HR QOL profile compared with imatinib, although the advantage of dasatinib was more pronounced in the younger age group, and negligible after the age of 60 years [15].

That imatinib is primarily reserved for elderly patients and second-generation TKIs are given to younger patients reflects our current practice. Dasatinib and nilotinib are more potent drugs. Patients on dasatinib or nilotinib achieve earlier responses and the rate of deeper molecular responses, that define candidates for treatment discontinuation, are higher [16-20]. Clinical trials that compared imatinib and second-generation TKIs in different settings reported that the safety profile of imatinib and second-generation TKIs are comparable. Yet, patients on dasatinib and nilotinib experience higher rates of serious adverse events that put elderly patients with age-related health problems at particular risk. For example, approximately $30 \%$ of patients on dasatinib will experience pulmonary edema $[19,21]$. Likewise, nilotinib carries a black box warning in the United States for possible heart complications and affects electrolytes and glucose balance $[20,22,23]$. Therefore, in otherwise healthy younger patients, giving second-generation TKIs for a more limited duration is the preferred choice when treatment discontinuation is the ultimate goal.

In conclusion, approximately $15 \%$ of Israeli patients with CML participated in this "real-life" study. At the time of survey, we found mostly elderly patients on imatinib and younger patients on either dasatinib or nilotinib. Not only is age associated with current TKI treatment, but it also predicts how patients perceive their QOL. Young patients that face serious illness, typically for the first time, express higher levels of distress and impaired QOL when compared to elderly patients.

Supplementary Materials: The following are available online at http://www.mdpi.com/2077-0383/9/11/3417/s1, Supplementary data 1: A survey booklet including: 1. A 30-item core questionnaire provided by the EORTC (EORTC QLQ-C30). 2. A 24-item CML-specific questionnaire, provided by the EORTC (EORTC QLQ-CML24). 3. Additional health-related items, added by authors.

Author Contributions: Conceptualization, P.R., U.R. and A.S.A.; methodology, U.R., A.S.A., P.R. and G.S.; software, U.R., A.S.A. and L.R.; formal analysis, U.R., A.S.A. and L.R.; investigation, A.S.A., U.R., S.S., L.R., T.B. and A.L.; writing—original draft preparation, A.S.A., U.R.; writing-review and editing, all authors: A.S.A., U.R., S.S., Tamar Berger, P.R., G.S. and L.R. All authors have read and agreed to the published version of the manuscript.

Funding: This research was funded by the the Israeli CML patients' organization.

Conflicts of Interest: Adi Shacham Abulafia-participated in advisory boards of Novartis, Pfizer and BMS. Pia Raanani-participated in advisory boards of Novartis, Pfizer, BMS and Incyte. Giora Sharf-participated in advisory boards of Novartis, Pfizer, BMS, Medisson, Takeda and Incyte. Uri Rozovski, Avi Leader, Sivan Shemesh, Tamar Bergerand Lena Rosenmann declare no conflict of interest.

\section{References}

1. Cohen, M.H.; Johnson, J.R.; Pazdur, R. U.S. Food and Drug Administration Drug Approval Summary: Conversion of imatinib mesylate (STI571; Gleevec) tablets from accelerated approval to full approval. Clin. Cancer Res. 2005, 11, 12-19. [PubMed]

2. Hoffmann, V.S.; Baccarani, M.; Hasford, J.; Castagnetti, F.; Di Raimondo, F.; Casado, L.F.; Turkina, A.; Zackova, D.; Ossenkoppele, G.; Zaritskey, A.; et al. Treatment and outcome of 2904 CML patients from the EUTOS population-based registry. Leukemia 2016, 31, 593-601. [CrossRef] [PubMed]

3. Efficace, F.; Cannella, L. The value of quality of life assessment in chronic myeloid leukemia patients receiving tyrosine kinase inhibitors. Hematology 2016, 2016, 170-179. [CrossRef] [PubMed]

4. Bower, H.; Björkholm, M.; Dickman, P.W.; Höglund, M.; Lambert, P.C.; Andersson, T.M.-L. Life Expectancy of Patients With Chronic Myeloid Leukemia Approaches the Life Expectancy of the General Population. J. Clin. Oncol. 2016, 34, 2851-2857. [CrossRef]

5. Sasaki, K.; Strom, S.S.; O’Brien, S.; Jabbour, E.; Ravandi, F.; Konopleva, M.; Borthakur, G.; Pemmaraju, N.; Daver, N.; Jain, P.; et al. Relative survival in patients with chronic-phase chronic myeloid leukaemia in the tyrosine-kinase inhibitor era: Analysis of patient data from six prospective clinical trials. Lancet Haematol. 2015, 2, e186-e193. [CrossRef] 
6. $\quad$ Phillips, K.M.; Pinilla-Ibarz, J.; Sotomayor, E.; Lee, M.R.; Jim, H.S.L.; Small, B.J.; Sokol, L.; Lancet, J.; Tinsley, S.; Sweet, K.; et al. Quality of life outcomes in patients with chronic myeloid leukemia treated with tyrosine kinase inhibitors: A controlled comparison. Support. Care Cancer 2012, 21, 1097-1103. [CrossRef] [PubMed]

7. Hochhaus, A.; Baccarani, M.; Silver, R.T.; Schiffer, C.; Apperley, J.F.; Cervantes, F.; Clark, R.E.; Cortes, J.E.; Deininger, M.W.; Guilhot, F.; et al. European LeukemiaNet 2020 recommendations for treating chronic myeloid leukemia. Leukemia 2020, 34, 966-984. [CrossRef]

8. Efficace, F.; Baccarani, M.; Breccia, M.; Saussele, S.; Abel, G.; Caocci, G.; Guilhot, F.; Cocks, K.; Naeem, A.; Sprangers, M.; et al. International development of an EORTC questionnaire for assessing health-related quality of life in chronic myeloid leukemia patients: The EORTC QLQ-CML24. Qual. Life Res. 2013, 23, 825-836. [CrossRef]

9. Fayers, P.M. Interpreting quality of life data. Eur. J. Cancer 2001, 37, 1331-1334. [CrossRef]

10. Guillemin, F.; Bombardier, C.; Beaton, D. Cross-cultural adaptation of health-related quality of life measures: Literature review and proposed guidelines. J. Clin. Epidemiol. 1993, 46, 1417-1432. [CrossRef]

11. Hendricson, W.D.; Russell, I.J.; Prihoda, T.J.; Jacobson, J.M.; Rogan, A.; Bishop, G.D.; Castillo, R. Development and initial validation of a dual-language english-spanish format for the arthritis impact measurement scales. Arthritis Rheum. 1989, 32, 1153-1159. [CrossRef] [PubMed]

12. Quinten, C.; Coens, C.; Ghislain, I.; Zikos, E.; Sprangers, M.A.G.; Ringash, J.; Martinelli, F.; Ediebah, D.E.; Maringwa, J.; Reeve, B.B.; et al. The effects of age on health-related quality of life in cancer populations: A pooled analysis of randomized controlled trials using the European Organisation for Research and Treatment of Cancer (EORTC) QLQ-C30 involving 6024 cancer patients. Eur. J. Cancer 2015, 51, 2808-2819. [CrossRef] [PubMed]

13. Bantema-Joppe, E.J.; De Bock, G.H.; Iersel, M.W.-V.; Busz, D.M.; Ranchor, A.V.; Langendijk, J.A.; Maduro, J.H.; Heuvel, E.R.V.D. The impact of age on changes in quality of life among breast cancer survivors treated with breast-conserving surgery and radiotherapy. Br. J. Cancer 2015, 112, 636-643. [CrossRef] [PubMed]

14. Pilkington, R.; Taylor, A.W.; Hugo, G.; Wittert, G. Are Baby Boomers Healthier than Generation X? A Profile of Australia's Working Generations Using National Health Survey Data. PLoS ONE 2014, 9, e93087. [CrossRef] [PubMed]

15. Efficace, F.; Stagno, F.; Iurlo, A.; Breccia, M.; Cottone, F.; Bonifacio, M.; Abruzzese, E.; Castagnetti, F.; Caocci, G.; Crugnola, M.; et al. Health-related quality of life of newly diagnosed chronic myeloid leukemia patients treated with first-line dasatinib versus imatinib therapy. Leukemia 2019, 34, 488-498. [CrossRef]

16. Etienne, G.; Guilhot, J.; Rea, D.; Rigal-Huguet, F.; Nicolini, F.; Charbonnier, A.; Guerci-Bresler, A.; Legros, L.; Varet, B.; Gardembas, M.; et al. Long-Term Follow-Up of the French Stop Imatinib (STIM1) Study in Patients With Chronic Myeloid Leukemia. J. Clin. Oncol. 2017, 35, 298-305. [CrossRef] [PubMed]

17. Campiotti, L.; Suter, M.B.; Guasti, L.; Piazza, R.; Gambacorti-Passerini, C.; Grandi, A.M.; Squizzato, A. Imatinib discontinuation in chronic myeloid leukaemia patients with undetectable BCR-ABL transcript level: A systematic review and a meta-analysis. Eur. J. Cancer 2017, 77, 48-56. [CrossRef]

18. Saussele, S.; Richter, J.; Guilhot, J.; Gruber, F.X.; Hjorth-Hansen, H.; Almeida, A.; Janssen, J.J.W.M.; Mayer, J.; Koskenvesa, P.; Panayiotidis, P.; et al. Discontinuation of tyrosine kinase inhibitor therapy in chronic myeloid leukaemia (EURO-SKI): A prespecified interim analysis of a prospective, multicentre, non-randomised, trial. Lancet Oncol. 2018, 19, 747-757. [CrossRef]

19. Cortes, J.E.; Saglio, G.; Kantarjian, H.M.; Baccarani, M.; Mayer, J.; Boqué, C.; Shah, N.P.; Chuah, C.; Casanova, L.; Bradley-Garelik, B.; et al. Final 5-Year Study Results of DASISION: The Dasatinib Versus Imatinib Study in Treatment-Naïve Chronic Myeloid Leukemia Patients Trial. J. Clin. Oncol. 2016, 34, 2333-2340. [CrossRef]

20. Hochhaus, A.; Saglio, G.; Hughes, T.P.; Larson, R.A.; Kim, D.-W.; Issaragrisil, S.; Le Coutre, P.D.; Etienne, G.; Dorlhiac-Llacer, P.E.; Clark, R.E.; et al. Long-term benefits and risks of frontline nilotinib vs imatinib for chronic myeloid leukemia in chronic phase: 5-year update of the randomized ENESTnd trial. Leukemia 2016, 30, 1044-1054. [CrossRef]

21. Cortes, J.; Jimenez, C.A.; Mauro, M.J.; Geyer, A.; Pinilla-Ibarz, J.; Smith, B.D. Pleural Effusion in Dasatinib-Treated Patients With Chronic Myeloid Leukemia in Chronic Phase: Identification and Management. Clin. Lymphoma Myeloma Leuk. 2017, 17, 78-82. [CrossRef] [PubMed] 
22. Steegmann, J.L.; Baccarani, M.; Breccia, M.; Casado, L.F.; García-Gutiérrez, V.; Hochhaus, A.; Kim, D.-W.; Kim, T.D.; Khoury, H.J.; Le Coutre, P.; et al. European LeukemiaNet recommendations for the management and avoidance of adverse events of treatment in chronic myeloid leukaemia. Leukemia 2016, 30, 1648-1671. [CrossRef] [PubMed]

23. Kim, T.D.; Réa, D.; Schwarz, M.; Grille, P.; Nicolini, F.E.; Rosti, G.; Levato, L.; Giles, F.J.; Dombret, H.; Mirault, T.; et al. Peripheral artery occlusive disease in chronic phase chronic myeloid leukemia patients treated with nilotinib or imatinib. Leukemia 2013, 27, 1316-1321. [CrossRef]

Publisher's Note: MDPI stays neutral with regard to jurisdictional claims in published maps and institutional affiliations.

(C) 2020 by the authors. Licensee MDPI, Basel, Switzerland. This article is an open access article distributed under the terms and conditions of the Creative Commons Attribution (CC BY) license (http://creativecommons.org/licenses/by/4.0/). 